\title{
A Network-based Contract Management Framework for Prioritizing Contractual Performance Progress Axis
}

\author{
Franck Cesar ${ }^{1}$, Franck Marle ${ }^{2}$ \\ ${ }^{1}$ WillBe Group, 22 rue de l'Arcade, Paris, FRANCE \\ ${ }^{2}$ Laboratoire Genie Industriel, CentraleSupélec, Université Paris-Saclay, 3 rue Joliot- \\ Curie, 91170 Gif-sur-Yvette, FRANCE

\begin{abstract}
Contracts play a major role in today's projects and operations. Contractual performance is defined as the result of the contract and the process and organization that support the contract lifecycle. It is determined by several interdependent factors, albeit they are generally managed without considering these interactions. A DSM is built to first identify potential relationships, either cause-effect or correlation, between contractual performance factors. This will allow for an easier and better decision about progress axis priorities in the field of Contract Management.
\end{abstract} \\ Keywords: Contract Management, network-based modeling, network-based \\ analysis, network-based decision, decision aiding
}

\section{Introduction}

Contracts play a major role in today's projects and operations. The way they are designed, awarded, executed and closed may strongly influence the performance of both clients and contractors.

\subsection{Contract}

Some examples of definitions are given as follows.

"An agreement between private parties creating mutual obligations enforceable by law. The basic elements required for the agreement to be a legally enforceable contract are: mutual assent, expressed by a valid offer and acceptance; adequate consideration; capacity; and legality. Possible remedies for breach of contract include general damages, consequential damages, reliance damages, and specific performance" (Kim 2017).

"A contract is an agreement giving rise to obligations which are enforced or recognized by law. The factor which distinguishes contractual from other legal obligations is that they are based on the agreement of the contracting parties" (McKendrick 2018).

"A contract is an agreement with the intent of creating one or several juridical obligations. It is a voluntary engagement, formal or informal, between two or more parties and recognized by law" (Barnett and Oman 2016).

Contract is thus a deliverable (document), designed, written, signed, executed, managed and closed by organizational entities / actors, following a specific process. At least two entities/actors are involved in a contract, often called Client and Contractor. More broadly, the contract implies the notion of stakeholders and their satisfaction at different moments of its lifecycle. A contract may be a unique, isolated operation, or may be integrated in a bigger one involving multiple contracts. In all cases, contracts have to be managed. 
Part I: Managing Organizations

\subsection{Contract Management}

According to the Chartered Institute of Purchasing and Supply, Contract Management $(\mathrm{CM})$ is "the process of systematically and efficiently managing contract creation, execution, and analysis for the purpose of maximizing financial and operational performance and minimizing risk" (CIPS 2007).

It is important to emphasize that $\mathrm{CM}$ is an organizational process and, for this reason, can be different from one organization to another. However, the need for CM is shared by any kind of organization, public and private, in order to reduce costs, deal with regulatory requirements, and more broadly improve performance.

\subsection{Contractual Performance}

If we consider contracts as the tangible output of an organizational process (as seen in the previous paragraph), "contractual performance" is defined by WillBe Group as the combination of three elements:

- Performance of the output (contract): the ability of the contract to satisfy the parties involved,

- Performance of the Contract Management process: the way of obtaining the output (efficiency),

- Performance of the organization that performs the Contract Management process.

The aim of a Contract Management Framework (CMF) is to provide a clear vision of where and how much progress has to be done, in the aim of improving (or maintaining or restoring) global and long-term contractual performance of the entity. As described in the rest of the paper, the first part of our research work consists of building a performanceoriented CMF. A perspective will be to relate this to classical risk management, considering the risk of non-contractual performance.

The remainder of the paper is as follows. Section 2 briefly introduces a survey about existing (and available) Contract Management Frameworks. This helps to build the research question, exposed in Section 3. Then, Section 4 introduces the research approach, which is executed in Section 5 with a first model of interdependent contractual performance factors. Section 6 will discuss about this first version and will draw some conclusions and perspectives.

\section{Background}

Contract Management Frameworks (CMF) are diverse and numerous, albeit with similarities, notably in terms of nature of organizational entity that provides them. It is obvious that other CMFs exist without being public, so our literature review is restricted to available information. CMFs have been found for mainly 4 types of organizations:

- Public organizations, at a national or local level, that audit procurement or purchasing-related activities (Department of Finance and Administration of Australian Government 2007; Department of Treasury and Finance Victoria State Government 2013; National Audit Office UK 2016; National Treasury Department of South Africa 2010). 
F. Cesar, F. Marle

- Public organizations, at a national or local level, that are clients for contracts with generally private contractors (Department of Health of Government of Western Australia 2012; Department of Housing and Public Works 2017; Municipal Association of Victoria 2018; Purchasing and Procurement Center of Malaysia 2017; Renewal SA 2015): the process is constrained by public regulations, so at least the award process should be public, but in some cases the entity publishes its overall process.

- Consulting companies, that aim at assisting either clients or contractors, like Deloitte (Anderson and Mendel 2017) or PriceWaterHouseCoopers (PriceWaterHouseCoopers 2010).

- Worldwide institutions, that aim at capturing best practices or just providing guidance and standards (World Bank 2017).

Most of them are process-oriented, describing either a sequential process, an iterative process or a cycle. They generally distinguish activities depending on their position before or after the contract signature:

- Upstream (or pre-award) activities: Preparing the business case and securing management approval; Assembling the project team; Developing contract strategy; Risk Assessment; Developing contract exit strategy; Developing a contract management plan; Drafting specifications and requirements; Establishing the form of contract; Establishing the pre-qualification, qualification $\&$ tendering procedures; Appraising suppliers; Drafting ITT (Invitation To Tender) documents; Evaluating tenders; Negotiating; Awarding the contract

- Downstream (or post-award) activities: Change management; Service delivery management; Relationship management; Contract administration; Risk reassessment; Purchasing organization's performance and effectiveness review; Contract closure

The next Section introduces their limits concerning complexity and introduces the academic question.

\section{Limits and Research Problem}

Complexity is recognized as influencing the way contracts are managed and their results (Caldwell, Roehrich, and Davies 2009; Jarkas 2017; Perona and Miragliotta 2004; Sivadasan et al. 2006). For instance, the CIPS (Chartered Institute of Procurement and Supply) cites increasing contract volumes and complexity as reasons to recognize the importance and benefits of Contract Management (CIPS 2007).

In some existing CMFs, efforts have been done to link contract management elements, often processes and often with time-related links (sequential links, phases, with or without overlap, cycles, ...). Some consequences of contract-related complexity are well-known, like for instance operational uncertainty, directly linked to financial risk (Beg 2015). However, some indirect effects, with possible propagations, or amplification, or retroaction, or variation (either of magnitude or even direction) of the links, are not well studied yet. It is thus a challenge to integrate the complexity of the contract management 


\section{Part I: Managing Organizations}

system, in order to improve contractual performance or increase risk of contractual performance.

The objective of the paper is thus to model interdependencies between factors of an existing Contract Management Framework, developed by the WillBe Group French consulting company. The justification of this question is that this model could be used for analyzing the CM factors network, in order to make easier and more reliable decisions about where to put priorities for performance improvement. The definition of these progress axis is today generally based on:

- models where factors are often considered as independent,

- analysis based on an individual assessment of performance or maturity,

- a decision-making process which does not simultaneously consider multiple parameters, like existing performance and importance of the factor, and required effort of the progress action.

All these reasons, operational need and literature gap, have justified the start of this research program, the first step being the network modeling project, presented here.

\section{Research method}

In this field, it is quite mandatory to be as close as possible of fieldwork, this is why we chose to use a constructivist approach (Mäkinen 1999), notably a Design Research Methodology-based approach, with alternation of prescriptive and descriptive study (Blessing and Chakrabarti 2009; Laurel 2003).

The target is an overall decision aiding process inspired by (Marle 2014), with a 3-step process, consisting of: 1/ modeling, 2/ analyzing a network, then $3 /$ making decisions considering specific complexity-oriented information obtained from previous steps. This paper focuses on step 1, the modeling of contractual performance factors network.

This step is based on the well-known DSM modeling technique, which emerged around thirty years ago and has spread, both in terms of volume of use and of nature of elements (Browning 2015, 2001; Eppinger and Browning 2012; Marle and Vidal 2008; Steward 1981). Classically, the DSM offers a compact structure for visualization of complex networks. Moreover, it allows for systematic exploration of potential interdependencies by navigating through rows and columns. The main hypothesis was that, to our knowledge, no similar network currently exists, and we argue that DSM is more suitable to create this network between such immaterial and intangible factors. The assumption was more about appropriation by users, both for building and manipulating this network.

This modeling project relies on four components:

- $\quad 1$ : internal experts' judgment (done)

- 2: literature review (done),

- 3: missions (ongoing),

- $\quad 4$ : clients' interviews (perspective at the moment of paper submission).

Two of them depend on external parameters and actors, with associated uncertainty (actual timeline and scope of missions, relevance of missions regarding the research question, number, adequacy and response time of interviewees). 


\section{F. Cesar, F. Marle}

One mission is currently ongoing with a possible link with the research. Authors hope that at the moment of the final submission of the paper, some additional information will have been provided by this fieldwork. Moreover, interviews will be structured and conducted with a refined version of the model, obtained by combining literature, internal experts' judgment and confrontation to the ongoing mission. This is planned for the end of 2019 start of 2020. After this initialization phase, a continuous change management process will be applied.

\section{Proposal of a first model of interdependencies between contractual performance factors}

This Section introduces, first the initial version of the CMF developed by WillBe Group, second the modeling principles for interdependence identification, and third the refined network-based version of the CMF.

\subsection{The initial 19-factor framework}

Based on a CMF literature review and expertise of internal consultants, numerous factors had been selected, renamed, merged or broken down in order to get the initial 19-factor framework developed by WillBe Group: F1-Contract type, F2-Contractor choice, F3-Risk allocation, F4-Governance quality, F5-Quality of execution control, F6-Abusive claims from the contractor, F7-Client opportunism, F8-Respect of mutual obligations, F9Interdependence between contractors, F10-Difference in clauses interpretation, F11Transaction Costs, F12-Input data, F13-Economic equilibrium, F14-Deliberate underestimation of constraints, F15-Incompleteness of information, F16-Evolution of needs, F17-Renegotiation ex-post, F18-Alignment to evolution (market, technology), F19Relational dimension.

The following paragraph illustrates how interdependencies are identified.

\subsection{The seek for interdependencies between these factors}

Interdependency exists when actions or events in one system affects or may affect elements in another system (Marle and Vidal 2016). Several authors introduced different types of interdependencies, like for instance:

- Klir and Valach with linear, circular and recursive interdependencies, in terms of causality of phenomena (Klir and Valach 1965).

- Thompson and later Browning with the parallel, the sequential, the coupled and the contingent dependencies (Browning 2001; Thompson 1967). The notion of temporal relative position between the two elements is still present, so as the notion of one-way or reciprocal dependency and the notion of sure or potential dependency.

- Le Moigne with interdependencies between three sub-systems: the decision system, the information system and the operational system (Le Moigne 1990).

- Marle with the hierarchical link (typically found in WBS), the contribution link (meaning that one element contributes to the advancement of the other one), the sequential link, the influence link (if a decision or a change in element 1 may 


\section{Part I: Managing Organizations}

involve a change in element 2), and the exchange link if the two elements have an information flow (Marle 2002).

- Worren with the commitment, the governance, the activity, the resource and the social interdependencies (Worren 2012).

An interdependency is thus described like in (Marle and Vidal 2016) through the characterization of which attribute(s) change(s), with a level of certainty (potential or sure) and of intensity (the number of attributes that change and the amount of change for each attribute). Attributes depend on the nature of elements, but classical attributes in contracts are related to cost, time, performance, and broadly speaking it describes the state of the element. This notion of attribute is not treated in this paper.

\subsection{The contractual performance factors network $v 1.0$}

Based on initial list of factors and on previously described strategy for interdependency identification, the initial version of the contractual performance DSM has been built.

While looking for interdependencies, we noticed that a factor, $F_{19}$, was linked with several ones, but in fact the links were more on a hierarchical nature (in terms of belonging to the same branch of a tree). We then considered this factor as a family of factors, this is why this updated version contains 18 factors. Moreover, in some cases, it is possible to give a sense to the positive or negative nature of a link. For instance, a good "Respect of mutual obligations" may decrease the necessity to run numerous controls and meetings, and then decrease "Transaction costs". However, other factors like "Contract type" and "Contractor choice" may be linked, albeit without any sense to an amplifying of retroactive effect. This is why for the moment we stay with positive values only, with this additional information on some specific cells.

Figure 2 hereunder represents the combined DSM, where each cell is the product of likelihood of interdependence and impact in case of interdependence. There are values from 1 to 9,9 meaning that the interdependency has the strongest likelihood and the strongest impact. This development has been done right before submission of revised paper. Analysis is still ongoing, but for now it seems that there are enough levels to discriminate interdependencies.

The reading convention for $(i, j)$ cell is: factor $F_{i}$ has an influence on factor $F_{j}$.

Next Section will discuss about results at date and next steps to reinforce the robustness of the model. 
F. Cesar, F. Marle

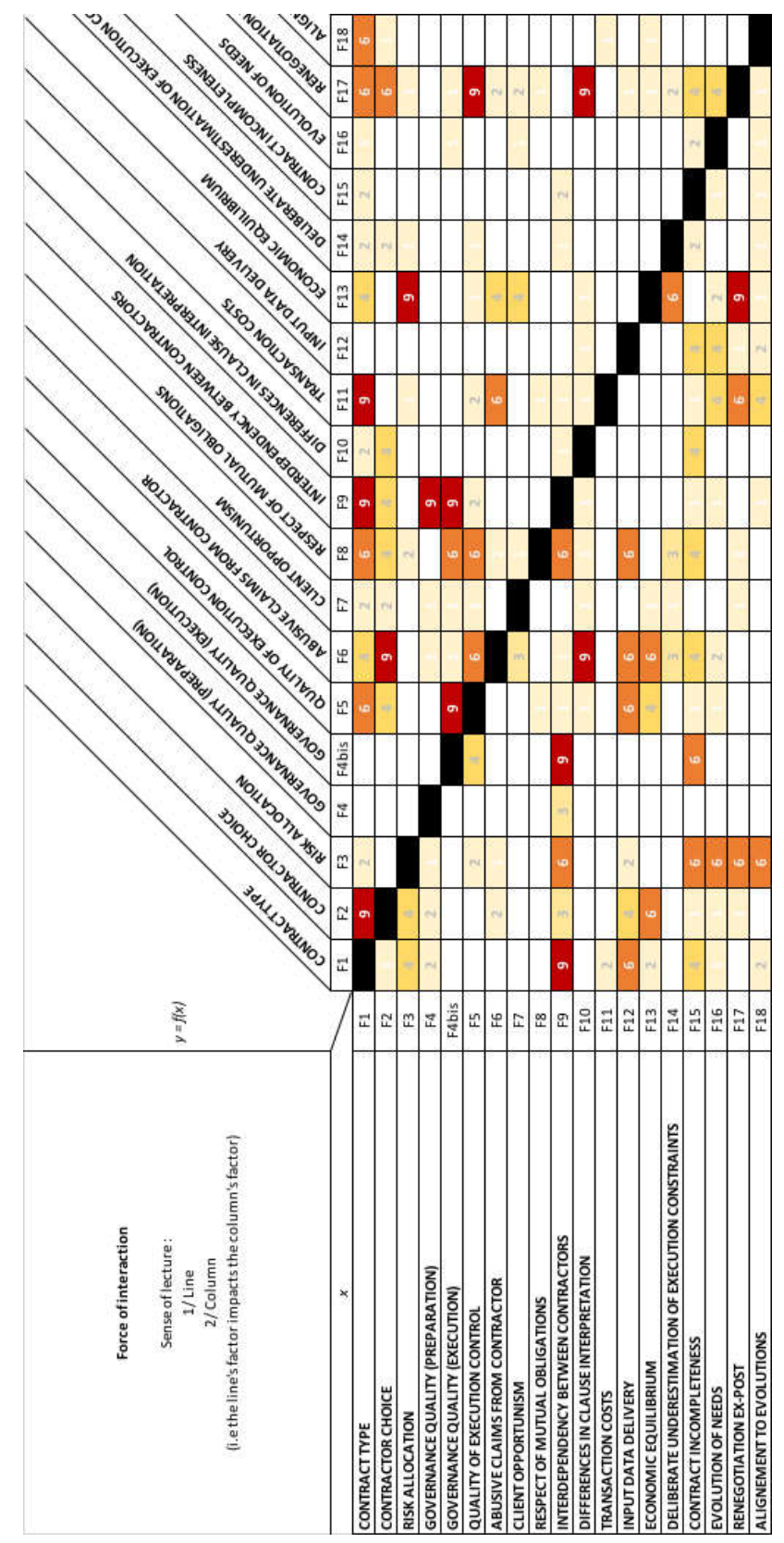

Figure 2: version 1 of the network-based CMF

\section{Discussion and perspectives}

Results of this first DSM-based modeling step are promising. The first lesson learnt is that factors list had to be adapted while considering interdependence between them. Questions 


\section{Part I: Managing Organizations}

arise about incorporating new factors, breaking existing ones down, merging other ones, and renaming some factors (for instance to improve clarity of definition and avoid overlaps). Another question arising from this initial work was the meaning of the cell. It is now after an iteration related to occurrence and impact of the interdependency.

Internal experts (from the consulting company) and current panel of external experts (from the client of the ongoing mission) recognize: 1/ the potential use of this model as an assistance to the prioritization of contract management progress actions; this may be helped by identification of key interdependences (strongest values in Figure 2), and possible chains and loops; 2 / the need to keep refining the network-based model and making it more robust, simultaneously generic but with the capacity to be quickly declined in specific contexts.

Future steps of this modeling project will consist in using maturity-based assessment of real organizations in order to: $1 /$ improve robustness of the network model by studying possible correlations between factors, depending on their maturity status; 2 / display factors list (and DSM) according to different sequences, the chronological vision being one of them (since there are factors that are clearly before or after contract signature, and some factors may be present all along the contract lifecycle); 3/ assess priorities for improvement, by combining maturity, importance and amount of work. This is inspired by previous work in automotive development context (González, Marle, and Bocquet 2007; Gonzalez Ramirez, Marle, and Bocquet 2008); 4/ group factors and the group actors according to the factors they are associated with and the links between these factors. This is inspired by other existing clustering works in nuclear construction and oil and gas sectors (Marle, Jaber, and Pointurier 2019; Ventroux, Marle, and Vidal 2018). 5/ finally, we realized that the link between factors and activities should be more explicit, and an MDMbased approach could help that. We will also try to relate performance factors to outcomes and results of both contract and contract management (we may have one time a good result but with poor contract management and in fact poor efficiency and high risk of failure on a next contract). More important for us is the relation between network consideration and final performance, meaning that our main assumption in complex systems (and DSM modeling) is that if they are not managed with a mental representation and understanding of their complexity, then decisions may be inadequate and involve failures or at least major waste (of time, money, energy, trust, ...).

\section{References}

Anderson, Jessica and Joseph Mendel. 2017. Enterprise Contract Management and Review Services. Retrieved (www.deloitte.com/us/about).

Barnett, Randy and Nathan Oman. 2016. Contracts: Cases and Doctrine, Sixth Edition. Wolters Kluwer Legal Education. Retrieved (http://www.wklegaledu.com/aspen-casebook-series/id9781454871033/contracts_cases_and_doctrine_sixth_edition).

Beg, Z. 2015. Complexity, Contract Design and Incentive Design in the Construction Management Industry. Retrieved (http://nrs.harvard.edu/urn-3:HUL.InstRepos:16881896).

Blessing, Lucienne T. M. and Amaresh Chakrabarti. 2009. DRM, a Design Research Methodology. London: Springer London. Retrieved (http://link.springer.com/10.1007/978-1-84882-587-1).

Browning, T. R. 2001. "Applying the Design Structure Matrix to System Decomposition and Integration Problems: A Review and New Directions." IEEE Transactions on Engineering Management 48(3):292-306. Retrieved 


\section{F. Cesar, F. Marle}

(http://ieeexplore.ieee.org/lpdocs/epic03/wrapper.htm?arnumber=946528).

Browning, Tyson R. 2015. "Design Structure Matrix Extensions and Innovations : A Survey and New Opportunities." IEEE Transaction on Engineering Management.

Caldwell, Nigel D., Jens K. Roehrich, and Andrew C. Davies. 2009. "Procuring Complex Performance in Construction: London Heathrow Terminal 5 and a Private Finance Initiative Hospital." Journal of Purchasing and Supply Management 15(3):178-86. Retrieved February 7, 2013 (http://linkinghub.elsevier.com/retrieve/pii/S1478409209000399).

CIPS. 2007. Contract Management Guide. Retrieved (https://www.cips.org/documents/CIPS_KI_Contract Management Guidev2.pdf).

Department of Finance and Administration of Australian Government. 2007. Developing and Managing Contracts. Retrieved (http://webarchive.nla.gov.au/gov/20120317003337/http://www.anao.gov.au/Publications/Be tter-Practice-Guides/2006-2007/Developing-and-Managing-Contracts).

Department of Health of Government of Western Australia. 2012. Contract Management Framework Health Information Network. Retrieved (http://www.parliament.wa.gov.au/parliament/commit.nsf/\%28\$lookupRelatedDocsByID\%2 9/BC320B2FE5518D3148257F94001B0C93/\$file/Contract+Management+Framework+201 2+HIN.pdf).

Department of Housing and Public Works. 2017. Queensland Government Procurement Contract Management Framework. Retrieved (http://www.hpw.qld.gov.au/SiteCollectionDocuments/OneGovernmentContractManagemen tFramework.pdf).

Department of Treasury and Finance Victoria State Government. 2013. Contract ManagementProcurement Guide.

Eppinger, S. D. and T. R. Browning. 2012. Design Structure Matrix Methods and Applications. MIT Press (MA).

González, N., F. Marle, and J. C. Bocquet. 2007. "Measuring Project Maturity: Example in a French Automotive Organization." in Proceedings of ICED 2007, the 16th International Conference on Engineering Design, vol. DS 42.

Gonzalez Ramirez, N., F. Marle, and JC. Bocquet. 2008. "Assessing Project Maturity: A Case Study." in PMI Research Conference. Warsaw, Poland.

Jarkas, Abdulaziz M. 2017. "Contractors' Perspective of Construction Project Complexity: Definitions, Principles, and Relevant Contributors." Journal of Professional Issues in Engineering Education and Practice 143(4):04017007. Retrieved (http://ascelibrary.org/doi/10.1061/\%28ASCE\%29EI.1943-5541.0000337).

Kim, Jonathan. 2017. "Contract | Wex Legal Dictionary / Encyclopedia.” LII / Legal Information Institute. Retrieved (https://www.law.cornell.edu/wex/contract).

Klir, J. and M. Valach. 1965. Cybernetic Modeling. London: ILiffe Books, Ltd. Retrieved (https://ia802901.us.archive.org/31/items/CyberneticModeling/Cybernetic Modeling.pdf).

Laurel, Brenda. 2003. Design Research: Methods and Perspectives. MIT Press. Retrieved (http://oskicat.berkeley.edu/record=b15960285 S1).

Mäkinen, S. 1999. "A Strategic Framework for Business Impact Analysis and Its Usage in New Product Development." Acta Polytechnica Scandinavica 2(1):213p.

Marle, Franck. 2014. "A Structured Process to Managing Complex Interactions between Project Risks.” International Journal of Project Organisation and Management 6(1/2):4-32.

Marle, Franck. 2002. "Modèles d'information et Méthodes Pour Aider à La Prise de Décision En Management de Projets." Ecole Centrale Paris. 
Part I: Managing Organizations

Marle, Franck, Hadi Jaber, and Catherine Pointurier. 2019. "Organizing Project Actors for Collective Decision-Making about Interdependent Risks.” Complexity 2019.

Marle, Franck and Ludovic-Alexandre Vidal. 2016. Managing Complex, High-Risk Projects. Springer.

Marle, Franck and Ludovic-Alexandre Vidal. 2008. "Potential Applications of DSM Principles in Project Risk Management.” Pp. 157-68 in International Design Structure Matrix Conference. Stockholm, Sweden.

McKendrick, Ewan. 2018. Contract Law: Text, Cases, and Materials. Eighth Edi. Oxford University Press, Oxford, UK.

Le Moigne, J. L. 1990. La Théorie Du Système Général. Théorie de La Modélisation. Paris, France: Presses Universitaires de France.

Municipal Association of Victoria. 2018. Contract Management Guidelines.

National Audit Office UK. 2016. Good Practice Contract Management Framework. Retrieved (www.nao.org.uk).

National Treasury Department of South Africa. 2010. Contract Management Guide. Retrieved (https://oag.treasury.gov.za/Publications/16. Contract Management/Guideline/Contract Management Guide - Ver 1.pdf).

Perona, Marco and Giovanni Miragliotta. 2004. "Complexity Management and Supply Chain Performance Assessment. A Field Study and a Conceptual Framework." International Journal of Production Economics 90(1):103-15. Retrieved October 10, 2012 (http://linkinghub.elsevier.com/retrieve/pii/S0925527302004826).

PriceWaterHouseCoopers. 2010. CONTRACT MANAGEMENT DIAGNOSTIC-OPERATIONAL CONSIDERATIONS. Retrieved (https://www.iia.org.uk/media/1022970/ContractManagement-Handout-PWC-.pdf).

Purchasing and Procurement Center of Malaysia. 2017. "Contract Management Process - Key Points and Activities." Retrieved (https://www.purchasing-procurement-center.com/contractmanagement-process.html).

Renewal SA. 2015. Contract Management Framework Pertaining to the Community Housing Agreement.

Sivadasan, S., J. Efstathiou, a. Calinescu, and L. Huaccho Huatuco. 2006. "Advances on Measuring the Operational Complexity of Supplier-Customer Systems." European Journal of Operational Research 171(1):208-26. Retrieved March 4, 2013 (http://linkinghub.elsevier.com/retrieve/pii/S0377221704005946).

Steward, D. 1981. "The Design Structure System: A Method for Managing the Design of Complex Systems." IEEE Transaction on Engineering Management 28:79-83.

Thompson, J. 1967. Organizations in Action. McGraw-Hill, New York.

Ventroux, J., F. Marle, and L. A. Vidal. 2018. "Organizational Reshuffling to Facilitate Coordinated Decisions in Complex Projects." Concurrent Engineering Research and Applications.

World Bank. 2017. Contract Management General Principles PROCUREMENT GUIDANCE. Retrieved (www.worldbank.org).

Worren, Nicolay. 2012. Organisation Design: Re-Defining Complex Systems. Pearson.

Contact: F. MARLE, Laboratoire Genie Industriel, CentraleSupélec, Université ParisSaclay, 3 rue Joliot-Curie, 91170 Gif-sur-Yvette, FRANCE 